Int. J. Electrochem. Sci., 12 (2017) $3873-3882$

\title{
Electrochemical Determination of Ascorbic Acid Based on Hydrothermal Synthesized ZnO Nanoparticles
}

\author{
Hang Zhu and Guifen Xu \\ Putian Univeristy, Dong Zhen West Road No. 450, Putian City, Fujian Province, 351100, P.R.China; \\ E-mail: journeysky@163.com
}

doi: $10.20964 / 2017.05 .48$

Received: 22 February 2017 / Accepted: 22 March 2017 / Published: 12 April 2017

In this work, $\mathrm{ZnO}$ nanoparticles (NPs) were prepared through an easy one-pot hydrothermal method. After synthesis, the obtained ZnO NPs were successfully adopted for surface modification of a glassy carbon electrode (GCE). The GCE modified with ZnO NPs was utilized to detect ascorbic acid (AA) in a sensitive and selective way. The biosensor revealed a linear correlation with AA concentration in the range of $1-800 \mu \mathrm{M}$, with a limit of detection of $0.312 \mu \mathrm{M}(\mathrm{S} / \mathrm{N}=3)$. The presented $\mathrm{AA}$ sensor manifested outstanding stability and repeatability and an anti-interference nature.

Keywords: ZnO; Hydrothermal synthesis; Electrochemical; Ascorbic acid; Sensor

\section{FULL TEXT}

(C) 2017 The Authors. Published by ESG (www.electrochemsci.org). This article is an open access article distributed under the terms and conditions of the Creative Commons Attribution license (http://creativecommons.org/licenses/by/4.0/). 